\title{
Capacidade antioxidante da própolis ${ }^{1}$
}

\author{
Adriane Alexandre Machado De-Melo², Adriana Hitomi Matsuda², \\ Alex da Silva de Freitas ${ }^{3}$, Ortrud Monika Barth ${ }^{4}$, Ligia Bicudo de Almeida-Muradian ${ }^{2}$
}

\begin{abstract}
Antioxidant activity of propolis

Propolis is a resinous substance collected by bees from many parts of plants and mixed with wax, pollen and salivary secretions. Its composition is complex and closely related to the vegetation features of each region. Thirty-three propolis samples were collected from four Brazilian regions (Northeast, Southeast, South and Central-West) and had their antioxidant activity analyzed by the connected oxidation of $\beta$-carotene/linoleic acid. A significant variation was observed for the antioxidant activity (51.33-92.70\%), according to the region where the sample was collected. The antioxidant activity of propolis samples collected in the Northeast region was lower than those collected in the Central-West, South and Southeast regions, respectively.
\end{abstract}

KEY-WORDS: Apis mellifera L.; $\beta$-carotene; linoleic acid.

\section{INTRODUÇÃO}

A própolis é uma substância resinosa, elaborada por abelhas a partir de partes de plantas, compreendendo cera, pólen e resinas, além de secreções das glândulas da cabeça das abelhas. É destinada a diferentes propósitos, na colmeia, tais como selar fissuras ou vedar espaços e embalsamar insetos invasores, evitando sua decomposição e o crescimento de micro-organismos que possam infectar a colônia (Bankova et al. 2000, Zunini et al. 2010).

Há relatos de que a própolis vem sendo utilizada há séculos e por diferentes povos, como os egípcios, para embalsamar seus mortos e evitar a putrefação dos corpos; pelos gregos e romanos, como agente antisséptico e cicatrizante; e pelos incas, como

\section{RESUMO}

A própolis é uma substância resinosa coletada de diversas partes das plantas por abelhas e misturada à cera, pólen e secreções salivares. Sua composição é complexa e está relacionada, principalmente, às características da vegetação de cada região. Trinta e três amostras de própolis foram coletadas em quatro regiões brasileiras (Nordeste, Sudeste, Sul e Centro-Oeste) e analisadas quanto à sua capacidade antioxidante, pela oxidação acoplada do sistema $\beta$-caroteno/ácido linoleico. Variação significativa na capacidade antioxidante $(51,33-92,70 \%)$ foi observada de acordo com a região onde a amostra foi coletada. A capacidade antioxidante das amostras de própolis da região Nordeste foi menor que a das amostras das regiões Centro-Oeste, Sul e Sudeste, respectivamente.

PALAVRAS-CHAVE: Apis mellifera L.; $\beta$-caroteno; ácido linoleico.

antipirético (Sforcin \& Bankova 2011). No Brasil, índios usavam a própolis elaborada por abelhas nativas meliponas (geoprópolis) na fabricação de ferramentas e como dádiva em sepultamentos (Barth et al. 2009).

As propriedades biológicas da própolis estão relacionadas à presença de uma variedade de compostos biologicamente ativos, cuja ação tem sido amplamente estudada. Pesquisas atribuem a esses compostos ação antioxidante, antimicrobiana, anti-inflamatória, anticarcinogênica e anti-HIV, entre outras (Ito et al. 2001, Montpied 2003, Alencar et al. 2007, Sawaya et al. 2011). Essas propriedades variam de acordo com as espécies de abelhas e plantas das quais é coletada a matéria-prima para sua elaboração (Salatino et al. 2005), bem como fatores como sazonalidade e tipo de coletor utilizado nas colmeias (Lima 2006).

1. Trabalho recebido em set./2013 e aceito para publicação em set./2014 ( $n^{\circ}$ registro: PAT 26497).

2. Universidade de São Paulo (USP), Faculdade de Ciências Farmacêuticas, Departamento de Alimentos e Nutrição Experimental, Laboratório de Análise de Alimentos, São Paulo, SP, Brasil.E-mails: adriane.melo@usp.br, adriana@cetal.com.br, ligiabi@usp.br.

3. Universidade Federal Fluminense (UFF), Laboratório de Geologia Marinha, Niterói, RJ, Brasil. E-mail: alexsilfre@gmail.com.

4. Universidade Federal do Rio de Janeiro (UFRJ), Instituto de Biologia, Departamento de Botânica, Laboratório de Palinologia, Rio de Janeiro, RJ, Brasil.E-mail: monikabarth@gmail.com. 
Antioxidantes são quaisquer substâncias que, quando presentes em baixas concentrações, em relação ao substrato oxidável, retardam ou inibem, consideravelmente, a sua oxidação (Thomas 2000).

Estudos sugerem que antioxidantes exógenos, quando presentes na dieta em quantidades significativas, contribuem para a prevenção de doenças graves e crônicas, como alguns tipos de câncer, cardiopatias, distúrbios metabólicos, doenças neurodegenerativas e enfermidades inflamatórias associadas à formação de radicais, durante o processo de oxidação (Carratu \& Sanzini 2005, Horst \& Lajolo 2011, Teerasripreecha et al. 2012, Daleprane \& Abdalla 2013).

Embora estudos indiquem a presença de compostos de natureza antioxidante na própolis (Laskar et al. 2010, Cabral et al. 2012, Daleprane \& Abdalla 2013, Fabris et al. 2013), diferentes métodos analíticos foram utilizados para determinar a capacidade de ação dessas substâncias, de modo que a falta de padronização limita a comparação entre os trabalhos já publicados.

Assim, este estudo objetivou identificar a capacidade antioxidante de amostras de própolis coletadas por abelhas Apis mellifera L., em quatro regiões brasileiras, e compará-las utilizando o método de oxidação acoplada do sistema $\beta$-caroteno/ ácido linoleico.

\section{MATERIAL E MÉTODOS}

Foram adquiridas 33 amostras de própolis in natura de abelha Apis melifera, entre os anos de 2003 e 2005, de apicultores e entrepostos de 11 Estados brasileiros (Bahia, Rio Grande do Norte, Maranhão, Paraíba, Minas Gerais, São Paulo, Rio de Janeiro, Paraná, Santa Catarina, Rio Grande do Sul, Mato Grosso do Sul), de quatro regiões do País (Nordeste, Sudeste, Sul, Centro-Oeste).

As amostras foram coletadas por raspagem das partes internas, bordas da melgueira, ninho e tampas das colmeias, acondicionadas em sacos plásticos de polietileno, identificadas e armazenadas ao abrigo da luz, a $5^{\circ} \mathrm{C}$, até o momento de envio, que ocorreu à temperatura ambiente, para o Laboratório de Análise de Alimentos da Faculdade de Ciências Farmacêuticas da Universidade de São Paulo. Uma vez no Laboratório, todas as impurezas foram retiradas para, em seguida, as amostras serem trituradas, peneiradas em tamis de 18 malhas ("mesh" de 1.000 micras), homogeneizadas, pesadas e armazenadas ao abrigo de luz, a $5^{\circ} \mathrm{C}$. As amostras foram analisadas à medida em que eram recebidas.

Os extratos foram preparados conforme Matsuda (2006). Balões de fundo chato contendo $0,4 \mathrm{~g}$ de própolis in natura triturada, previamente desidratada em estufa a $60^{\circ} \mathrm{C}$, por 2 horas, e $20 \mathrm{~mL}$ de metanol PA foram incubados a $60^{\circ} \mathrm{C}$, em banho de água termostatizado, por 1 hora, sob agitação constante. Em seguida, os extratos foram centrifugados a $3.000 \mathrm{rpm}$, por 10 minutos, em centrífuga Hermle Z 320. Os sobrenadantes foram filtrados por papel filtro (Advantec 5A, com 0,06 mg de cinzas/90 mm), para tubos de ensaio. Uma segunda extração foi realizada nas mesmas condições, utilizando-se o resíduo da primeira extração. Os sobrenadantes obtidos das duas extrações foram homogeneizados e armazenados em frascos âmbar, a $5^{\circ} \mathrm{C}$.

A capacidade antioxidante foi determinada pela oxidação acoplada do sistema $\beta$-caroteno/ ácido linoleico (Alencar 2002, Kumazawa et al. 2003, Matsuda 2006). Em um béquer, foram adicionados $20 \mu \mathrm{L}$ de $\beta$-caroteno, $40 \mu \mathrm{L}$ de ácido linoleico e $300 \mathrm{mg}$ de Tween 40, os quais foram dissolvidos em $1 \mathrm{~mL}$ de clorofórmio, que foi evaporado, posteriormente, sob nitrogênio. $\mathrm{O}$ resíduo obtido da evaporação foi dissolvido em $100 \mathrm{~mL}$ de água deionizada oxigenada e $5 \mathrm{~mL}$ da solução foram transferidos para tubos de ensaio contendo uma alíquota do extrato de própolis equivalente à concentração de 100 ppm (com base na quantidade de sólidos solúveis retirados na extração). Os tubos foram incubados a $40^{\circ} \mathrm{C}$, para a reação de oxidação e a manutenção da cor alaranjada do $\beta$-caroteno, e a reação foi acompanhada em espectrofotômetro, pela medida de absorbância a $470 \mathrm{~nm}$, em intervalos de 60 minutos, durante o período de 3 horas, sendo que a primeira leitura foi realizada à temperatura ambiente.

Todas as determinações foram feitas em triplicata e acompanhadas por um controle sem antioxidantes e outro com solução de butilhidroxitolueno (BHT). A capacidade antioxidante foi calculada por meio da seguinte fórmula: $\% \mathrm{CA}=$ 100 - DAA/DAC x 100, em que CA = capacidade antioxidante, DAA = decaimento de absorbância da amostra e DAC = decaimento de absorbância do controle.

A análise polínica das amostras brutas de própolis foi realizada de acordo com a metodologia de Barth (1998) e Barth et al. (1999). Amostras de 
0,5 g de própolis triturada foram transferidas para tubos de centrífuga, e a eles adicionados $15 \mathrm{~mL}$ de álcool etílico absoluto. Os tubos foram mantidos à temperatura ambiente por, no mínimo, 24 horas, com agitação ocasional. $\mathrm{O}$ álcool etílico foi removido por centrifugação (2.500 rpm; 15 minutos), sendo o processo repetido quando visualmente notava-se elevada concentração de cera.

Após a centrifugação, o sobrenadante foi dividido em dois tubos de centrífuga e, a cada tubo, foram adicionados $13 \mathrm{~mL}$ de álcool etílico absoluto, para nova centrifugação. A cada resíduo, foram adicionados $12 \mathrm{~mL}$ de solução de hidróxido de potássio a $10 \%$ e os tubos submetidos a aquecimento em banho-maria, por 3 minutos, a $90^{\circ} \mathrm{C}$.

Para evitar a formação de grumos e facilitar a liberação do pólen, foi aplicado aos tubos, imediatamente após a etapa de aquecimento, ultrassom, por 5 minutos. Após sonificação, os tubos foram centrifugados ( $2.500 \mathrm{rpm}$; 15 minutos) e o sedimento lavado com $13 \mathrm{~mL}$ de água destilada, filtrado em tela de malha $(0,3 \mathrm{~mm}$ de abertura) e novamente centrifugado (2.500 rpm; 15 minutos). Foram preparadas duas lâminas de microscopia, para visualização dos pelos vegetais.

A seguir, foram adicionados $5 \mathrm{~mL}$ de ácido acético glacial aos tubos contendo o sedimento, permanecendo por uma noite. Após nova centrifugação (2.500 rpm; 15 minutos), foi realizada a acetólise, ou seja, a oxidação do sedimento com $5 \mathrm{~mL}$ de uma mistura de anidrido acético e ácido sulfúrico $(9: 1 ; \mathrm{v} / \mathrm{v})$, em banho-maria, até alcançar a temperatura de $80^{\circ} \mathrm{C}$, por cerca de 3 minutos. Após cuidadosa lavagem em água destilada $(2 \mathrm{x}) \mathrm{e}$ em água-glicerinada $(1: 1 ; \mathrm{v} / \mathrm{v})$ (por 30 minutos), foram montadas duas lâminas de microscopia, utilizando-se gelatina glicerinada, uma com e outra sem corante (fucsina básica), vedando-se com parafina. Para a observação de pelos vegetais, preparou-se uma lâmina do sedimento, antes da aplicação da mistura de acetólise.

A identificação dos grãos de pólen e respectivas interpretações relacionadas à vegetação foram fundamentadas em dados da literatura (Barth 1989, Roubik \& Moreno 1991), sendo os mesmos designados pelo nome da família botânica, gênero ou espécie ao qual se assemelhavam.

A capacidade antioxidante das amostras de própolis foi comparada com base na região de coleta, pelo teste de Mood, a 5\% (Costa-Neto 1977).

\section{RESULTADOS E DISCUSSÃO}

Os resultados de determinação da capacidade antioxidante dos extratos de própolis, em estudo no sistema $\beta$-caroteno/ácido linoleico, estão apresentados na Tabela 1. A determinação por esse sistema é muito utilizada, uma vez que o $\beta$-caroteno é altamente suscetível à ação de radicais. A descoloração (oxidação) do caroteno é induzida pelos produtos da degradação oxidativa do ácido linoleico (Kumazawa et al. 2003, Matsuda 2006) e o sistema avalia a capacidade de a amostra evitar a oxidação de substratos lipídicos (Duarte-Almeida et al. 2006).

Com a aplicação do teste de Mood, pôde-se verificar que as amostras de própolis das quatro regiões brasileiras não apresentaram níveis iguais de capacidade antioxidante $(\mathrm{p}<0,001)$ (Figura 1). As amostras de própolis da região Sudeste apresentaram-se superiores às das regiões Sul e Centro-Oeste, sendo as amostras dessas duas regiões estatisticamente semelhantes. Observou-se que as amostras das regiões Nordeste e Sudeste apresentaram maior e menor variabilidade nos níveis de capacidade antioxidante, respectivamente.

Ikegaki (2001) avaliou a capacidade antioxidante de amostras de própolis da região Sul do Brasil e encontrou valores entre $65,50 \%$ e $95,10 \%$, de modo que a média observada para essa região, no presente estudo $(77,79 \%)$, encontra-se nessa faixa. Na região Sul, uma grande diversidade vegetal está à disposição das abelhas para coleta, o que resulta na ocorrência de variados tipos de própolis (Park et al. 2002).

Silva (2008), ao avaliar quatro amostras de própolis do Estado de Minas Gerais, observou valo-

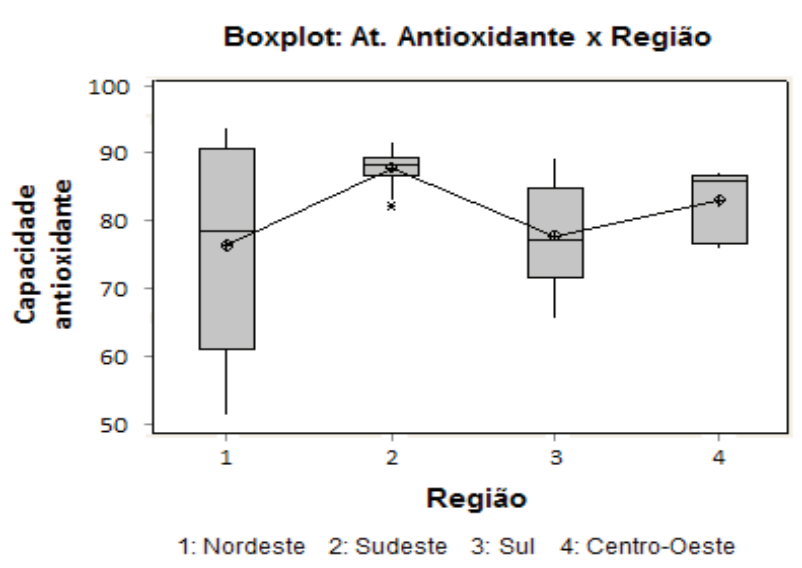

Figura 1. Relação entre a capacidade antioxidante das amostras de própolis, em função das quatro regiões brasileiras. 
Tabela 1. Capacidade antioxidante dos extratos metanólicos das amostras brutas de própolis coletadas em quatro regiões do Brasil.

\begin{tabular}{|c|c|c|c|}
\hline Região & Estado & Município & $\begin{array}{l}\text { Capacidade antioxidante } \pm \mathrm{DP}(\%) \\
\text { Extratos }-100 \mathrm{ppm}\end{array}$ \\
\hline \multirow{8}{*}{ Nordeste } & \multirow{4}{*}{ Bahia } & Mucuri & $90,28 \pm 0,48$ \\
\hline & & Irecê & $77,02 \pm 0,45$ \\
\hline & & Palmeiras & $80,33 \pm 0,58$ \\
\hline & & Lençóis & $69,74 \pm 0,48$ \\
\hline & Rio Grande do Norte & João Câmara & $57,85 \pm 0,43$ \\
\hline & Maranhão & São Luiz & $51,33 \pm 0,49$ \\
\hline & \multirow{2}{*}{ Paraíba } & Santa Terezinha & $91,61 \pm 0,43$ \\
\hline & & João Pessoa & $92,70 \pm 0,37$ \\
\hline \multirow{12}{*}{ Sudeste } & \multirow{5}{*}{ Minas Gerais } & Barbacena & $83,73 \pm 0,45$ \\
\hline & & Itabira & $88,40 \pm 0,55$ \\
\hline & & Lavras & $90,55 \pm 0,54$ \\
\hline & & Patrocínio & $89,48 \pm 0,49$ \\
\hline & & Juiz de Fora & $89,40 \pm 0,52$ \\
\hline & \multirow{5}{*}{ São Paulo } & Salesópolis & $86,59 \pm 0,55$ \\
\hline & & Barra do Chapéu & $88,46 \pm 0,65$ \\
\hline & & Paraibuna & $83,67 \pm 0,65$ \\
\hline & & Cajamar & $88,58 \pm 0,58$ \\
\hline & & Pilar do Sul & $86,97 \pm 0,60$ \\
\hline & \multirow{2}{*}{ Rio de Janeiro } & Itaboraí & $90,35 \pm 0,80$ \\
\hline & & Paraíba do Sul & $88,38 \pm 0,78$ \\
\hline \multirow{10}{*}{ Sul } & \multirow{4}{*}{ Paraná } & São José da Boa Vista & $70,43 \pm 0,76$ \\
\hline & & São Mateus do Sul & $85,64 \pm 0,54$ \\
\hline & & Wenceslau Brás & $78,20 \pm 0,71$ \\
\hline & & Ivaí & $81,70 \pm 0,75$ \\
\hline & \multirow{4}{*}{ Santa Catarina } & Içara & $84,83 \pm 0,50$ \\
\hline & & Anitápolis & $65,92 \pm 0,53$ \\
\hline & & Itajaí & $88,55 \pm 0,76$ \\
\hline & & Araranguá & $76,57 \pm 0,53$ \\
\hline & \multirow{2}{*}{ Rio Grande do Sul } & Pelotas & $71,43 \pm 0,66$ \\
\hline & & Taquara & $74,67 \pm 0,61$ \\
\hline \multirow{3}{*}{ Centro-Oeste } & \multirow{3}{*}{ Mato Grosso do Sul } & Campo Grande & $86,52 \pm 0,58$ \\
\hline & & Mundo Novo & $86,38 \pm 0,75$ \\
\hline & & Angélica & $76,24 \pm 0,66$ \\
\hline
\end{tabular}

res de até $84,11 \%$, abaixo do máximo observado no presente estudo (90,55\%), para a amostra de Lavras, também no Estado de Minas Gerais. Cabral et al. (2009) avaliaram uma amostra de própolis do Estado de Alagoas e observaram capacidade antioxidante de até $64,84 \%$, após o fracionamento do extrato com clorofórmio. Ukulo et al. (2013) avaliaram amostras de própolis coletadas em quatro distritos do Quénia e observaram capacidade antioxidante de $54,49-$ $68,84 \%$, enquanto Choi et al. (2013) constataram índice de, no máximo, 50,00\%, em 18 amostras de própolis coletadas em diferentes regiões da Coreia do Sul.

A influência fitogeográfica sobre as características da própolis poderia explicar variações observadas entre as amostras (Barth et al. 2013). Na busca pela caracterização geográfica da procedência da própolis, bem como da sua origem vegetal, análises qualitativas e quantitativas dos grãos de pólen presentes na própolis podem servir como indicativo (Barth et al. 1999). Na Tabela 2, são apresentados os resultados da análise qualitativa das 33 amostras de própolis, com a identificação dos grãos de pólen mais frequentes.

Bastos (2001), analisando espectro polínico e fragmentos de epiderme, tricomas tectores e tricomas glandulares de Baccharis dracunculifolia, em amostras de própolis do Estado de Minas Gerais, observou pólen característico de Eucalyptus, como no presente estudo, além de Vernonia, Astronium e Hyptis.

Grãos de pólen do tipo Mimosa, Arecaceae, Borreria densiflora, B. latifolia, B. verticillata, 
Tabela 2. Resultados da análise qualitativa dos grãos de pólen mais frequentes das amostras de própolis bruta coletadas em quatro regiões do Brasil.

\begin{tabular}{|c|c|c|c|c|}
\hline Região & Estado & Município & Grãos de pólen & Pólen mais frequente \\
\hline \multirow{7}{*}{ Nordeste } & \multirow{4}{*}{ Bahia } & Mucuri & ++++ & $\begin{array}{c}\text { Solanaceae, Borreria verticillata, Arecaceae, } \\
\text { Sapindaceae }\end{array}$ \\
\hline & & Irecê & ++++ & Mimosa verrucosa \\
\hline & & Palmeiras & + & Mimosa \\
\hline & & Lençóis & ++ & Arecaceae \\
\hline & Rio Grande do Norte & João Câmara & $(+)$ & SDA \\
\hline & Maranhão & São Luiz & NA & NA \\
\hline & Paraíba & $\begin{array}{l}\text { Santa Terezinha } \\
\text { João Pessoa }\end{array}$ & $\begin{array}{c}++++ \\
++ \\
\end{array}$ & $\begin{array}{c}\text { SDA } \\
\text { Eucalyptus }\end{array}$ \\
\hline \multirow{3}{*}{ Sudeste } & Minas Gerais & $\begin{array}{l}\text { Barbacena } \\
\text { Itabira } \\
\text { Lavras } \\
\text { Patrocínio } \\
\text { Juiz de Fora }\end{array}$ & $\begin{array}{c}++ \\
+ \\
++ \\
++ \\
++\end{array}$ & $\begin{array}{c}\text { Eucalyptus } \\
\text { Asteraceae } \\
\text { SDA } \\
\text { Eucalyptus } \\
\text { Eucalyptus, Asteraceae }\end{array}$ \\
\hline & São Paulo & $\begin{array}{l}\text { Salesópolis } \\
\text { Barra do Chapéu } \\
\text { Paraibuna } \\
\text { Cajamar } \\
\text { Pilar do Sul }\end{array}$ & $\begin{array}{l}+ \\
+ \\
+ \\
++ \\
++ \\
++\end{array}$ & $\begin{array}{c}\text { Eucalyptus, Asteraceae } \\
\text { Asteraceae, Solanaceae } \\
\text { Eucalyptus } \\
\text { Eucalyptus } \\
\text { Eucalyptus, Asteraceae }\end{array}$ \\
\hline & Rio de Janeiro & $\begin{array}{l}\text { Itaboraí } \\
\text { Paraíba do Sul }\end{array}$ & $\begin{array}{l}(+) \\
(+) \\
\end{array}$ & $\begin{array}{l}\text { SDA } \\
\text { SDA }\end{array}$ \\
\hline \multirow{3}{*}{ Sul } & Paraná & $\begin{array}{l}\text { São José da Boa Vista } \\
\text { São Mateus do Sul } \\
\text { Wenceslau Brás } \\
\text { Ivaí }\end{array}$ & $\begin{array}{c}++ \\
+ \\
+ \\
++\end{array}$ & $\begin{array}{c}\text { SDA } \\
\text { Asteraceae } \\
\text { SDA } \\
\text { Asteraceae }\end{array}$ \\
\hline & Santa Catarina & $\begin{array}{l}\text { Içara } \\
\text { Anitápolis } \\
\text { Itajaí } \\
\text { Araranguá }\end{array}$ & $\begin{array}{l}++++ \\
++++ \\
++ \\
++\end{array}$ & $\begin{array}{l}\text { Eucalyptus } \\
\text { Eucalyptus } \\
\text { Eucalyptus } \\
\text { SDA }\end{array}$ \\
\hline & Rio Grande do Sul & $\begin{array}{l}\text { Pelotas } \\
\text { Taquara }\end{array}$ & $\begin{array}{l}+++ \\
+++\end{array}$ & $\begin{array}{c}\text { SDA } \\
\text { Eucalyptus, Asteraceae }\end{array}$ \\
\hline Centro-Oeste & Mato Grosso do Sul & $\begin{array}{l}\text { Campo Grande } \\
\text { Mundo Novo } \\
\text { Angélica }\end{array}$ & $\begin{array}{l}(+) \\
(+) \\
(+)\end{array}$ & $\begin{array}{l}\text { SDA } \\
\text { SDA } \\
\text { SDA }\end{array}$ \\
\hline
\end{tabular}

(+): muito raro; +: raro; ++: pouco; +++: médio; ++++: muito; NA: não avaliado; S.D.A.: sem pólen dominante ou acessório (pólen dominante: frequência superior a $45 \%$; pólen acessório: frequência entre $15 \%$ e $45 \%$ ).

Myrcia e Schinus aff. terebinthifolius foram observados em amostras de própolis vermelha provenientes da região Nordeste (Alagoas e Bahia) (Barth \& Luz 2009). Resultados semelhantes foram encontrados no presente estudo, para amostras de própolis provenientes da Bahia.

Chama a atenção a ocorrência de pólen característico de Eucalyptus, principalmente nas regiões Sudeste e Sul, fato que parece relacionado ao cultivo de várias espécies de eucalipto, nessas regiões (Freitas et al. 2010 e 2011).

Além de Eucalyptus, pólen de Asteraceae foi observado, com certa frequência, nas amostras de própolis das regiões Sudeste e Sul (Barth et al.
2013), enquanto, na região Nordeste, foi identificada variedade maior de fontes vegetais.

Estudos indicam que, no Brasil, algumas das principais fontes vegetais para elaboração de própolis são as espécies Dalbergia ecastophyllum (rabo-de-bugio), Baccharis dracunculifolia (alecrim do campo), Araucaria angustifolia (pinheiro brasileiro) e Eucalyptus citriodora (eucalipto), com outras espécies visitadas em menor proporção (Bankova 2005, Alencar et al. 2007, Silva et al. 2007). Os resultados obtidos pelo presente estudo mostram que outras fontes de exsudados vegetais também são importantes.

A análise dos grãos de pólen presentes na própolis, embora sugestiva, não pode ser utilizada 
para afirmar sua origem vegetal, somente a sua procedência fitogeográfica. Embora as amostras tenham apresentado grãos de pólen dominante ou acessório da mesma procedência, em sua composição, não se sabe se esse pólen resulta da visita de abelhas destinada à coleta de matéria-prima, para a elaboração exclusivamente de própolis, ou se é resultante de contaminação da amostra pelas abelhas, durante a execução de outras atividades. Tanto na amostra de própolis de João Pessoa (PB) quanto na amostra de Barbacena (MG), o pólen de Eucalyptus foi observado como dominante, mas a capacidade antioxidante nas amostras foi de $92,70 \%$ e $83,73 \%$, respectivamente. Certos componentes químicos da própolis podem advir de fontes botânicas cujo pólen não foi incorporado à amostra, ou mesmo das próprias abelhas, influenciando no perfil químico (Teixeira et al. 2003).

A literatura existente aponta correlação positiva entre a capacidade antioxidante e o teor de compostos fenólicos na própolis (Cabral et al. 2009, Cottica et al. 2011), principalmente com flavonoides (Alencar et al. 2007), fenilpropanoides prenilados (Salatino et al. 2005) e compostos específicos, como o ácido 3,5-diprenil-4-hidroxicinâmico (Artepillin C) (Matsuda \& Almeida-Muradian 2008) e o ácido cafeico (Gregoris \& Stevanato 2010).

A capacidade antioxidante de flavonoides e polifenóis parece estar relacionada ao número e à disposição dos grupos hidroxila nas moléculas (Gregoris \& Stevanato 2010, Pietta 2000). De-Melo et al. (2012) observaram quantidades variáveis de fenólicos totais e, especificamente, de flavonoides totais, em amostras de própolis coletadas nas regiões Nordeste, Sul, Sudeste e Centro-Oeste do Brasil. Cabral et al. (2012) apontam que outros compostos, além dos fenólicos, podem ser responsáveis pela capacidade antioxidante da própolis.

Os métodos químicos são excelentes indicadores de capacidade antioxidante (Heirich et al. 2008), ou seja, são utilizados como screening para que, em seguida, as melhores amostras tenham sua capacidade antioxidante avaliada em ambientes biológicos (Zunini et al. 2010) e, por fim, ensaios clínicos (Sforcin \& Bankova 2011).

Zunini et al. (2010) avaliaram 19 amostras de própolis da região Centro-Sul do Uruguai, pelo método do DPPH e por ensaio de peroxidação lipídica microssomal, utilizando microssomas de fígado isolados de ratos Wistar. Nesse último, a atuação dos compostos antioxidantes ocorreu em ambiente biológico, um cenário mais complexo que o do teste químico do método do DPPH. Os autores observaram que certos compostos estão mais ou menos potentes, de acordo com o ambiente de teste, e que sua atuação está relacionada a fatores como a estrutura química do antioxidante, que pode, em alguns casos, dificultar o acesso do composto a estruturas complexas, como microssomas.

\section{CONCLUSÕES}

1. Das amostras de própolis coletadas e analisadas pela oxidação acoplada do sistema $\beta$-caroteno/ ácido linoleico, somente duas apresentaram capacidade antioxidante abaixo de $60 \%$, ambas da região Nordeste. As amostras da região Sudeste apresentaram a maior capacidade antioxidante, seguidas das provenientes das regiões Centro-Oeste, Sul e Nordeste.

2. A análise polínica revelou presença predominante de pólen de Eucalyptus, principalmente nas regiões Sudeste e Sul, e maior variedade de tipos polínicos nas amostras do Nordeste.

\section{AGRADECIMENTOS}

Ao Conselho Nacional de Desenvolvimento Científico e Tecnológico (CNPq), pelas bolsas de produtividade em pesquisa, e ao Laboratório Cetal, pelo apoio técnico, durante a coleta de dados.

\section{REFERÊNCIAS}

ALENCAR, S. M. Estudo fitoquímico da origem botânica da própolis e avaliação da composição química de mel de Apis mellifera africanizada de diferentes regiões do Brasil. 2002. 120 f. Tese (Doutorado em Ciência de Alimentos) - Faculdade de Engenharia de Alimentos, Universidade Estadual de Campinas, Campinas, 2002.

ALENCAR, S. M. et al. Chemical composition and biological activity of a new type of Brazilian propolis: red propolis. Journal of Ethnopharmacology, Lausanne, v. 113, n. 2, p. 278-283, 2007.

BANKOVA, V. Chemical diversity of propolis and the problem of standardization. Journal of Ethnopharmacology, Lausanne, v. 100, n. 1/2, p. 114-117, 2005.

BANKOVA, V. S.; CASTRO, S. L.; MARCUCCI, M. C. Propolis: recent advances in chemistry plant origin. Apidologie, Versailles, v. 31, n. 1, p. 3-15, 2000. 
BARTH, O. M. O pólen no mel brasileiro. Rio de Janeiro: Luxor, 1989.

BARTH, O. M. Pollen analysis of Brazilian propolis. Grana, Stockholm, v. 37, n. 2, p. 97-101, 1998.

BARTH, O. M.; BARROS, M. A.; FREITAS, F. O. Análise palinológica em amostras arqueológicas de geoprópolis do vale do Rio Peruaçu, Januária, Minas Gerais, Brasil. Arquivos do Museu de História Natural e Jardim Botânico, Belo Horizonte, v. 19, n. 1, p. 277-290, 2009.

BARTH, O. M.; DUTRA, V. M. L.; JUSTO, R. L. Análise polínica de algumas amostras de própolis do Brasil meridional. Ciência Rural, Santa Maria, v. 29, n. 4, p. 663-667, 1999.

BARTH, O. M. et al. Botanical origin and Artepillin-C content of Brazilian propolis samples. Grana, Stockholm, v. 52, n. 2, p. 1-7, 2013.

BARTH, O. M.; LUZ, C. F. P. Palynological analysis of Brazilian red propolis samples. Journal of Apicultural Research, London, v. 48, n. 3, p. 181-188, 2009.

BASTOS, E. M. A. F. Origem botânica e indicadores de qualidade da "própolis verde" produzida no Estado de Minas Gerais. 2001. 137 f. Tese (Doutorado em Entomologia) - Faculdade de Filosofia, Ciências e Letras de Ribeirão Preto, Universidade de São Paulo, Ribeirão Preto, 2001.

CABRAL, I. S. R. et al. Composição fenólica, atividade antibacteriana e antioxidante da própolis vermelha brasileira. Química Nova, São Paulo, v. 32, n. 6, p. 15231527, 2009.

CABRAL, I. S. R. et al. The correlation between the phenolic composition and biological activities of two varieties of Brazilian propolis (G6 and G12). Brazilian Journal of Pharmaceutical Sciences, São Paulo, v. 48, n. 3, p. 557564, 2012.

CARRATU, E.; SANZINI, E. Sostanze biologicamente attive presenti negli alimenti di origine vegetable. Annali dell' Instituto Superiore di Sanitá, Roma, v. 41, n. 1, p. 7-16, 2005.

CHOI, S. J. et al. Antioxidant properties and phenolic composition of propolis from diverse geographic regions in Korea. Food Science and Technology Research, Ibaraki, v. 19, n. 2, p. 211-222, 2013.

COSTA-NETO, P. L. O. Estatística. São Paulo: Edgard Blücher, 1977.

COTTICA, S. M. et al. Antioxidant activity and composition of propolis obtained by different methods of extraction. Journal of the Brazilian Chemical Society, São Paulo, v. 22, n. 5, p. 929-935, 2011.
DALEPRANE, J. B.; ABDALLA, D. S. Emerging roles of propolis: antioxidant, cardioprotective, and antiangiogenic actions. Evidence-based Complementary and Alternative Medicine, New York, v. 2013, n. 1, p. 1-8, 2013.

DE-MELO, A. A. M. de; MATSUDA, A. H.; ALMEIDAMURADIAN, L. B. de. Identidade e qualidade da própolis proveniente de quatro regiões do Brasil. Revista do Instituto Adolfo Lutz, São Paulo, v. 71, n. 3, p. 540-548, 2012.

DUARTE-ALMEIDA, J. M. et al. Avaliação da atividade antioxidante utilizando sistema $\beta$-caroteno/ácido linoleico e método de sequestro de radicais DPPH. Ciência e Tecnologia dos Alimentos, Campinas, v. 26, n. 2, p. 446452, 2006.

FABRIS, S. et al. Antioxidant properties and chemical composition relationship of European and Brazilian propolis. Pharmacology \& Pharmacy, London, v. 4, n. 1, p. 46-51, 2013.

FREITAS, A. S. et al. Palynological analysis of Brazilian propolis samples. Journal of ApiProduct and ApiMedical Science, Dallas, v. 3, n. 2, p. 67-74, 2011.

FREITAS, A. S.; LUZ, C. F. P.; BARTH, O. M. Própolis marrom da vertente atlântica do Estado do Rio de Janeiro, Brasil: uma avaliação palinológica. Revista Brasileira de Botânica, São Paulo, v. 33, n. 2, p. 341-352, 2010.

GREGORIS, E.; STEVANATO, R. Correlations between polyphenolic composition and antioxidant activity of Venetian propolis. Food Chemistry, London, v. 48, n. 1, p. 76-82, 2010.

HEINRICH, M. et al. Herbal extracts used for upper respiratory tract infections: are there clinically relevant interactions with the Cytochrome P450 enzyme system? Planta Med, Berlin, v. 74, n. 6, p. 657-660, 2008.

HORST, M. A.; LAJOLO, F. M. Biodisponibilidade de compostos bioativos de alimentos. 2011. Disponível em: <www.fcf.usp.br>. Acesso em: 02 fev. 2012.

IKEGAKI, M. Determinação de qualidade de própolis de Apis mellifera africanizada da região Sul do Brasil: avaliação de algumas propriedades físico-químicas e biológicas da própolis. 2001. $74 \mathrm{f}$. Tese (Doutorado em Ciências de Alimentos) - Faculdade de Engenharia de Alimentos, Universidade Estadual de Campinas, Campinas, 2001.

ITO, J. et al. Anti-AIDS agents. 48. Anti-HIV activity of moronic acid derivatives and the new mellifore-related triterpenoid isolated from Brazilian propolis. Journal of Natural Products, Cincinnati, v. 64, n. 1, p. 1278-1281, 2001.

KUMAZAWA, S. et al. Direct evidence for the plant origin of Brazilian propolis by the observation of honeybee 
behavior and phytochemical analysis. Chemical and Pharmaceutical Bulletin, Tokyo, v. 51, n. 6, p. 740-742, 2003.

LASCAR, R. A. et al. Antioxidant activity of Indian propolis and its chemical constituents. Food Chemistry, London, v. 122, n. 1, p. 233-237, 2010.

LIMA, M. G. A produção de própolis no Brasil. São João da Boa Vista: Unifeob, 2006.

MATSUDA, A. H. Caracterização e controle de qualidade de própolis proveniente de diversas regiões do Brasil. 2006. 123 f. Dissertação (Mestrado em Ciência dos Alimentos) - Faculdade de Ciências Farmacêuticas, Universidade de São Paulo, São Paulo, 2006.

MATSUDA, A. H.; ALMEIDA-MURADIAN, L. B. Validated method for the quantification of Artepillin $C$ in Brazilian propolis. Phytochemical Analysis, Sussex, v. 19, n. 2, p. 179-183, 2008.

MONTPIED, P. Caffeic acid phenethyl ester (CAPE) prevents inflammatory stress in organotypic hippocampal slice cultures. Molecular Brain Research, Amsterdam, v. 115, n. 2, p. 111-120, 2003.

PARK, Y. K. et al. Própolis produzida no Sul do Brasil, Argentina e Uruguai: evidências fitoquímicas de sua origem vegetal. Ciência Rural, Santa Maria, v. 32, n. 6, p. 997-1003, 2002.

PIETTA, P. G. Flavonoids as antioxidants. Journal of Natural Products, Cincinnati, v. 63, n. 7, p. 1035-1042, 2000.

ROUBIK, D. W.; MORENO, J. E. Pollen and spores of Barro Colorado Island. St. Louis: Missouri Botanical Garden, 1991.

SALATINO, A. et al. Origin and chemical variation of Brazilian propolis. Evidence-based Complementary and Alternative Medicine, New York, v. 2, n. 1, p. 33-38, 2005.
SAWAYA, A. C. H. F.; CUNHA, I. B. S.; MARCUCCI, M. C. Analytical methods applied to diverse types of Brazilian propolis. Chemistry Central Journal, London, v. 27, n. 5, p. 1-10, 2011.

SFORCIN, J. M.; BANKOVA, V. Propolis: is there a potential for the development of new drugs? Journal of Ethnopharmacology, Lausanne, v. 133, n. 2, p. 253-260, 2011.

SILVA, B. B. et al. Chemical composition and botanical origin of red propolis, a new type of Brazilian propolis. Evidence-based Complementary and Alternative Medicine, New York, v. 5, n. 3, p. 313-316, 2007.

SILVA, C. C. F. Análise química e atividades antioxidante e citotóxica de amostras de própolis de alecrim. 2008. 110 f. Dissertação (Mestrado em Ciências) - Instituto de Biociências, Universidade de São Paulo, São Paulo, 2008.

TEERASRIPREECHA, D. et al. In vitro antiproliferative/ cytotoxic activity on cancer cell lines of a cardanol and a cardol enriched from Thai Apis mellifera propolis. BMC Complementary and Alternative Medicine, London, v. 30, n. 1, p. 12-27, 2012.

TEIXEIRA, E. W. et al. Indicadores da origem botânica da própolis: importância e perspectivas. Boletim de Indústria Animal, Nova Odessa, v. 60, n. 1, p. 83-106, 2003.

THOMAS, M. J. The role of free radicals and antioxidants. Nutrition, New York, v. 16, n. 7/8, p. 8-16, 2000.

UKULO, J. W. et al. Antioxidative and radical scavenging activities of propolis extracts in food models. African Journal of Food, Agriculture, Nutrition and Development, Nairobi, v. 13, n. 1, p. 7273-7287, 2013.

ZUNINI, M. P. et al. Phenolic contents and antioxidant activity in central-southern Uruguayan propolis extracts. Journal of the Chilean Chemical Society, Concepción, v. 55, n. 1, p. 141-146, 2010. 